\title{
LEARNING OF VOCATIONAL SKILL FOR EMPOWERMENT THE SPIRIT OF SPECIAL NEEDS OF CHILDREN
}

\author{
Arwan Wiratman, Ivo Yuliana, Roihana M.W \\ Post Graduate Program Surabaya State University \\ E-mail: arwan.wiratman17@gmail.com
}

\begin{abstract}
The child with special needs has barriers on the function of the development Several aspects of emotional, physical and mental or any of aspects. The child with special needs has learning modalities that enable them to make-adaption with Reviews their environments. They need independence to adapt. One of the approaches to establish Reviews their independency is through the learning skills to develop self-help and economic activity. Reviews These are two vital aspect for the independence of the child with special needs.
\end{abstract}

Keywords: skilss learning, vocational learning models, self-reliance

\section{INTRODUCTION}

Education in Indonesia has developed quite rapidly. One is the development of the use of the term Special Education is currently intended for children with special needs (ABK). Serving the entire special education students who have problems and special needs in learning. According to Shea \& Bauer (1997) students with disabilities disaggregated by the condition of specificity, namely: (1) a learner who vary in their interactions (2) learner who vary in Accessing the environment (3) learner who vary in their learning styles and rates. The specificity of each disaggregated bears more appropriate barriers (such as: children with behavioral barriers, barriers of children with sight and children with mental barriers). The variation specificity Polloway and Patton (1993) suggested that educational services for the crew adapted to the needs of children. If the school can not provide services throughout the program needs of the child, it should cooperate with other agencies, but still the responsibility of the crew in place school enrolled. Education of children with special needs (ABK) in regular schools and special schools (SLB), essentially to help children develop their potential. The purpose of learning these skills to equip the crew to have a useful job skills after school. Implementation of the development of these skills in high school outstanding (SMALB) for mental retardation programs emphasize skills class (SLB Pembina observations from Makassar, 2017). These conditions indicate the existence of concern to equip schools for graduates of vocational skills. To facilitate the vocational learning most of SLB equipped with workshops (shelterworkshop), and cooperative marketing. Through the production and marketing units are expected to work in the learning process skills can be introduced and got a sale value in society. In addition SLB can also accept orders according to the type of products people skills in schools. 
Vocational learning management on its behalf is not easy. If it is associated with a potential crew varied and individualized. On the other hand ABK conditions are still in the early stages of learning vocational abilities, certainly not able to produce the quality of production that meet market requirements. More specifically on ABK conditions with lower mental abilities (children with intellectual challenges), it takes longer to learn the skills and only able to complete one or two parts of one type of product (Amin, 1995). However ABK type of mental retardation have modalities repeating one kind of work and he was serious at work. This ABK if trained continuously be able to work with the results marketable.

The review of the curriculum content level education unit (SBC) in 2007 for the subjects of Arts and Skills (SBK) for ABK, explains that competence skills learning leads to the kind of vocational skills together with the curriculum SBK in regular schools (among other things: cookery, hairdressing clothing, carpentry, agriculture, automotive, services, music, traditional and modern dance as well as skill-based high technology). The scope of this competence to hope for the crew to have special skills in the form of one of the working skills in addition to academic skills as learning outcomes. In the concept of life skills included in the scope of the specific life skills-SLS in addition tolearning outcomes general life skills (Anwar, 2004). Mastery of these two aspects of life skills, such as the main stock for each individual (including crew) to self-adapt in life. It is also the basis for determining the skills to level SMLB class.

Based on observations in the school there are several issues that diahadapi teachers. Some things about the conduct of vocational education, among others: (1) the establishment of teaching material and content of the material has not fully focused on the needs of students. Learning is based on material in the curriculum, (2) the purpose of learning the skills most schools still as subjects that must be implemented. The learning objectives have not been formulated to achieve the learning outcomes or skill of functional skills and pre-vocational and vocational life for post-school provision, (3) skill learning strategy is still limited to classroom learning skills. Most schools have not implemented the contract learning strategies in collaboration with parents and do not take the apprenticeship system work in an institution or place of business accordingly, (4) learning resources have not used a replica or a real environment. Medium of learning in most schools still seem modest and has not been managed effectively (eg, children bring equipment from home or using school equipment are not yet utilizing the technology, (5) lack of school membelajarkan marketing capabilities work crews. The results of learning skills was limited to graded by the teacher. This means that the school has not been optimal functioning of the cooperative school and other events for the marketing of products by students, (6) assessment of learning outcomes have not applied the criteria of the achievement of performance based on skill level (primary, skilled level and advanced 
level) and have not applied the test skills of independent work. Assessment still oriented to fill out report cards end of the semester, (7) Human Resources (HR) teachers are not entirely competent mastery of the content meteri and how the learning skills of the crew. Most teachers are classroom teachers, and not entirely follow deepening training penguas ABK aan skills learning.

\section{Skills and Life Skills learning forABK}

Life skills necessaryevery individual in an effort to survive. Life skills does not appear by itself but as one of the skills developed through learning. The concept of life skilss in the school system, according to the Directorate General of Public Education (2002) are classified into two categories, namely (1) general life skills (generic skills) that include: personal skills (skills to know myself / self awareness, rational thinking skills / thikingskills), social skills, and (2) the specific life skills (specific skills) include: academic skills and vocational skills.

Anwar (2004) states thateducation life skills in formal school distinguished by hierarchically. For kindergarten (kindergarten), elementary school (SD), Junior High School (JSS) emphasized todevelopment of the generallife skills (GLS), whereasskills the specificlife skills (SLS) limited the introduction stage. At the school level (SMA / K) emphasized the stabilization of general life skills (GLS) and the development of specific life skills (SLS) for the provision of continuing higher education or enter the labor sector. The concept of education life skills are similar to the education ABK described by Hallahan and Kauffman (1991) that its behalf in the base class and middle (aged 9-13 years) need to focus the learning skills of maturity to help themselves or skills of daily living and academic functional ( such as reading the newspaper labels, counting the shopping, filling out forms). For adults and adolescents aged ABK SLB learning more emphasis on the development aspects of vocational skills training and social responsibility.

Based on the concept of life skills show that independence can be achieved if the crew had self-help skills, academic skills or functional academic and vocational skills. According direktoran led DG PLSP, 2003, there are four basic requirements in the development of life skills, namely (1) the skills developed based on the interests and needs of the individual, (2) related to the characteristics of the potential of local areas, natural resources and socio-cultural, (3) developed significantly as a small business or industry sector households, (4) oriented towards improving the competence of the applicative skills to work operationally.

To achieve the learning outcomes required skills for ABK repetitive exercise to make a habit of life. Types of skills tailored to the talents and interests of ABK. Coverage of minimum teaching materials include the ability to help themselves or activities of daily living, skills to work. Preferably skills to work have one type of job or sub-job, which can be achieved quality of mastery 
of learning outcomes by ABK. Armed with such vocational ABK might develop or work on other parties to obtain a decent income recognition. Of course learning model requires sisterm management skills that involve various stakeholders are functionally (ABK parents, schools, industrial or business units and related government and society). Thus ABK independence can be achieved through education skills, if there is recognition by the environment on the results of the performance of the crew.

\section{Directions Learning Skills For ABK}

DirectionsThere are four types of learning skills for ABK. These types adapted to the level of specificity of ABK. According to Smith \& lucasson (1992) level of specificity ABK classified into three gradations, namely: Mild (ABK with mild conditions), Moderate (ABK with moderate conditions), and Serve (ABK with severe conditions). Associated with these groupings are also described the so-called Consideration for Individualized Determination of LRE. In this concept, there are several components associated with service for crew members in accordance with individual conditions, namely: intensity of services, duration of services, types of personnel, location of service, and instructional considerations. From this view illustrates that the needs and problems of learning ABK vary greatly. Thus the educational service skills can not be uniform in terms of both kinds of skills, teaching materials, learning time, structuring the learning environment (classroom setting), and learning strategies.

Associated with the grouping condition Ishartiwi ABK (2002) presented a conceptual study on Directions Learning Skills To ABK diagram of one to four of the following. Discussion direction of learning these skills are not presented in detail for each type of specificity. Model Directions learning these skills apply to all types of specificity. This is what distinguishes the charge, the weight, depth and breadth of teaching materials as well as the manner of presentation and management of learning.

The principle of the application of model towards learning skills for ABK: (1) the type of skills adapted to the conditions and limitations (2) educational materials skills adapted to the environment ABK life after school, (3) learning with contract system, school, family, vocational training centers center, job training, or a container of labor, (4) the scope of learning include: general life skills(generallifeskills),job skills, (5) learning is not solely for the fulfillment of the school curriculum but oriented independence early, (6) the learning skilled and proficient levels do after school with BLB institution / business community, (7) the school serves as a social rehabilitation unit crew and provide basic pre-vocational skills, (8) vocational learning flexible, continuous, direct practice (real life) and over and over re, (9) the experience of vocational 
competency achievement with a certificate (license employment) bi sa through "labor organization ABK", (10) there is a commitment of government and society to labor crews.

Conceptual study each direction of learning skills for self-reliance as follows:

\section{Directions Learning Skills for crew members with Category Light}

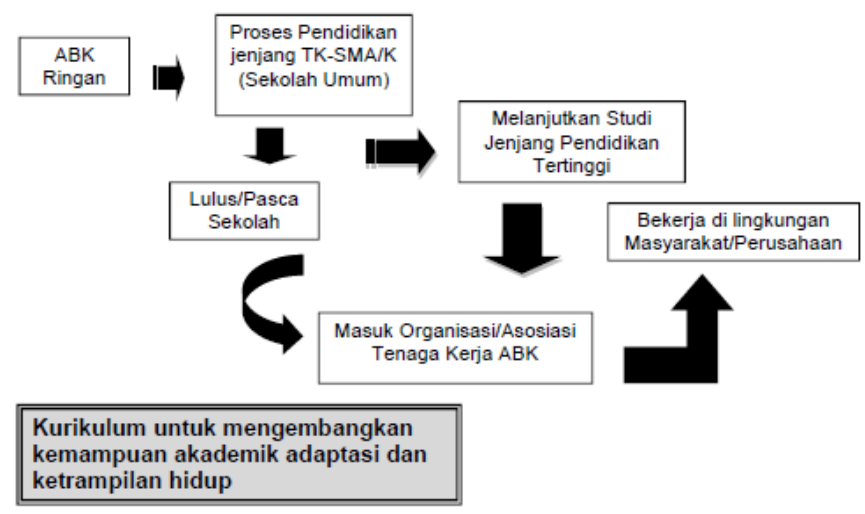

\section{Diagram 1. Skills Learning System ABK Category Lightweight}

ABK soft criteria in the exposure condition is explained by the conditions: (1) The crew did not have the complexity of specificity clothing, (2) normal ABK intelligence, (3) ABK easily make adaptations in their environment, (4) the crew did not have many obstacles to move in life.

ABK skills learning program for light can be equated with normal children a regular school with the adjustment manner of presentation and content of teaching materials based on the needs of the crew. Towards learning includes two objectives, namely: (1) the direction of learning for preparation continue to pursue more education, so it is more focused on academic skills and personal social and (2) to prepare the crew enter the working world. In this case the crew can learn all kinds of skills. Furthermore, post-graduate ABK good school for middle school and higher education institutions are obliged to follow education in association / organization $\mathrm{ABK}$ labor. This institution serves as a transition from institutional schooling to the world of work. The role played by these institutions provide educational supplies for crews working to get a certificate of advanced level of competency certain types of work and to test self-employment training through internships in the workplace. Based on these competencies ABK placed in institutions appropriate work.

\section{Directions Learning Skills for crew members with Category Medium}

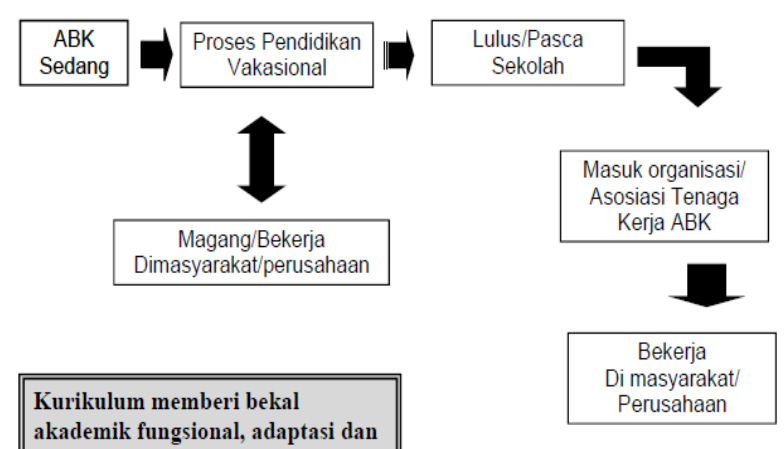




\section{Diagram 2 Learning System skills ABK Category Average}

Criteria condition ABK being indicated by the conditions: (1) ABK has the complexity of specificity, (2) intelligence ABK below the normal average, (3) ABK experiencing barriers for adaptation in the environment, (4) the crew requires a special tool to move in life.

ABK pembelajaan skills program for middle category is focused on developing academic skills and lenih right school segregation or special schools (SLB). Through the intervention program in the school segregation medium category $\mathrm{ABK}$ get tailor-made service individually. Profram purpose of learning skills for ABK kategiru medium for preparation entered the workforce. Emphasized teaching materials to achieve the development of functional academic skills, adaptive skills and one type of appropriate work skills ABK capabilities. Skills learning process executed by the school through internships in the workplace according to the type of learning program of the skills taught. Direct internship process is done considering the medium category ABK intelligence capability is limited so they need real situation in learning or doing direct the actual work environment. Then the post-graduate school of education in the institution is obliged to follow the association / organization ABK labor. This institution serves as a transition from institutional schooling to the world of work. The role played by this institution of learning keterampilankerja deepen its behalf that have the ability to advanced level (level of workability as required post-school employment ABK). In addition to obtain competency certificates advanced level of certain types of work through independent exercise test. Based on these competencies ABK placed in institutions appropriate work.

\section{Directions Learning Skills for crew members with Category Weight}

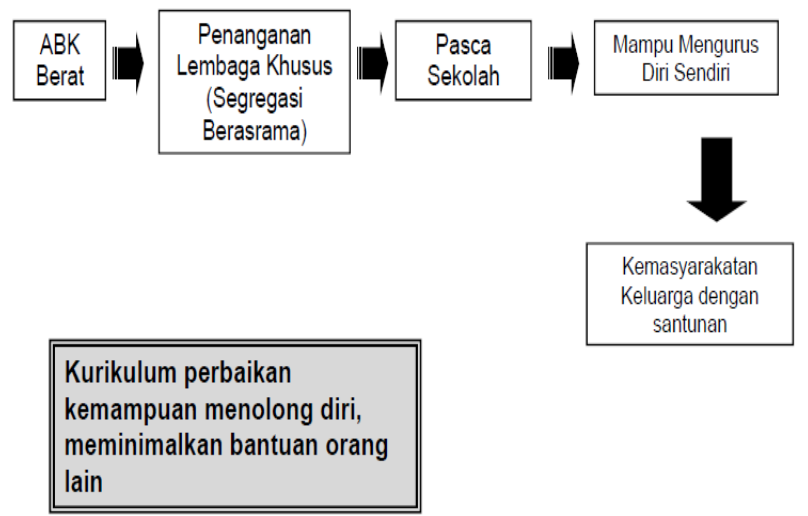

Diagram 3 System Learning Skills for ABK category Weight

Criteria condition ABK minimum weight include: (1) ABK bears the variation specificity which greatly hindered the development and capabilities in life (2) intelligence ABK very low or included in lowest categories, (3) ABK face many obstacles to adapt their 
environment, (4) ABK requires special tools and guidance continuously to conduct activities in life.

ABK skills learning program for weight categories emphasized in order to achieve selfhelp capabilities for those who can afford. But for ABK conditions are very severe, the program emphasized that they may perform physical movements despite very limited. Learning teaching materials cover the activities of helping themselves in everyday life. ABK with weight categories that have the ability to work although very limited (able to complete part or subsections one type of work) need to be trained for the work ability of domestic work sector. The minimal work to meet the needs of self-ABK. Directions learning skills ABK aims to reduce the assistance of others in meeting the activities of daily life. Thus the content and presentation of learning materials as well as benchmark the learning outcomes developed according to individual needs. In this case the crew can learn practical activities. Implementation of learning in a boarding school segregation or even given educational services in the family. Learning is done within the scope of a place to stay ABK. Learning time is very flexible, meaning that the corresponding ability of children achieving learning outcomes in the form of habit-forming performance. Furthermore, post-school (after ABK mastering the skills learned in maximum) remains guided social life. In this case the people around $\mathrm{ABK}$ weight categories need to participate actively provide guidance that $\mathrm{ABK}$ with weight categories can live independently in their environment. Thus, learning skills of crews with heavy category ABK continues throughout life.

\section{Directions Learning Skills for crew members with Category Unprecedented School of}

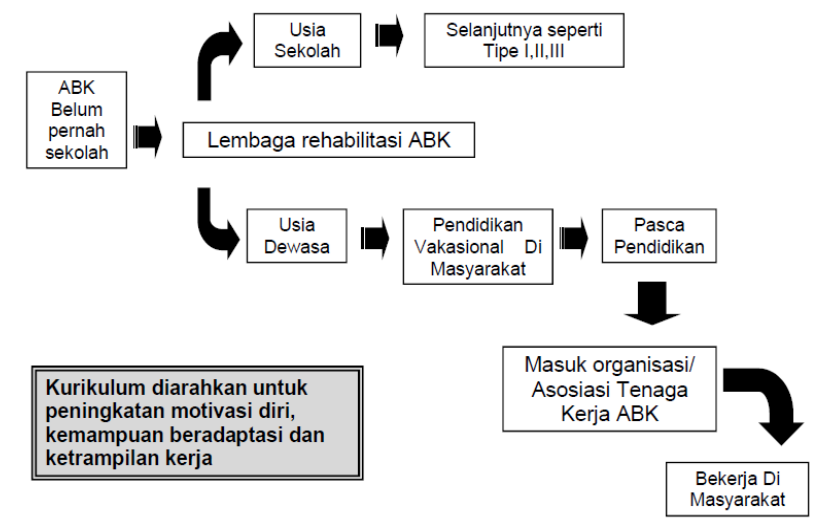

\section{Diagram 4 Vocational Education System ABK Category Unprecedented School}

Criteria have never attended school ABK conditions are classified into two crews have never attended school but still includes ABK school age and adult age have never attended school. ABK conditions include categories of mild, moderate and severe. 
ABK skills learning programs for schools category has never started with the intervention in rehabilitation institutions. Rehabilitation is intended to provide a transitional program for preparation for entering the ketermpilan learning program. Intervention in the rehabilitation institute emphasized special program or prerequisite learning program development and physical and mental preparation for learning skills. The next step ABK given appropriate intervention group, namely: ABK school age have never attended school learning implementation skills to choose the model towards learning skills in the diagram 1,2,3, and 4 tailored to the age and condition of specificity ABK. ABK have never attended school for older age groups are given skills learning program through internships in the business world in accordance with the type of post pekerjaab as vocational education. Post basic level training and skill levels of the organization continued special internship / labor associations $\mathrm{ABK}$ to undertake self-employment exercise test and get a certificate of competence. Directions learning skills to ABK group is aiming to equip skills of one type of work that interest ABK. Based on these competencies ABK placed in suitable employment agency work.

\section{CONCLUSION}

Learning the skills to distinguish between ABK ABK with mental conditions low, normal, and above normal and a result of the complexity barriers of specialization. Essential components and is fundamental to learning functional skills for ABK are: (1) the courage and school policies that decisively to enforce the learning curriculum-based skills interests, talents and needs work after school, (2) learning which can not be restricted period of school and or only limited during school hours, to achieve the learning outcomes skills in independence level vocational / economic activity (advanced), (3) learning the skill is done in the real atmosphere, to enable the participation of business partners, (4) the role of parents ABK is also very important to follow and practice the skills of learning outcomes in everyday life, it is more for the functional skills to help themselves to the crew with lower mental abilities. if necessary to apply the learning model contracts, (5) the creativity of teachers have a significant impact ABK skill learning, (6) for the empowerment of selfreliance through learning the skills necessary $\mathrm{ABK}$ public recognition of the competence or working performance of the crew. 


\section{BIBLIOGRAPHY}

Amin.1995. OrtopedagogikMentally Retarded Children. Jakarta: Directorate of Higher Education, Ministry of Education and Culture.

Richard I. Arends 2007. Learning T Teach. Translation: Helly Prayitno S and Sri Mulyani S 2008 Edition 1. Yogyakarta: Student Library.

Anwar. 2004. Life Skills Education: Concepts and Applications. Bandung: Alfabeta.

Berni, BC, Ittenback, RF \& Patton, JR 2002. Mental Retartdation. Ohio: Merrill Prentice Hall.

Ciptono and Ganjar Triadi. 2009. Outstanding Teacher. Bandung: Landscape Reader.

Dryden, G., Jeanette Vos. 1999. The Learning Revolution, The Learning Web. New Zeland.

Hallahan, DP., Kauffman, JM 1991. Exceptional Children: Introduction to Special Education. Fifth Edition. New Prentice Hall International. Inc.

Hergenhahn BR \& Olson Matthew H. 2008. Theories of Learning. Translation: Triwibowo BS 2009 Mold 2. Jakarta: Kencana.

Ishartiwi. 2002. developing a life skills of children with disabilities Based On Intelligence Multiplen. Papers Teacher Training SLB. Yogyakarta.

Polloway Edward A \& Patton James R. 1993. Strategies for Teaching Learners with Special Needs. USA: Macmillan Publishing Company.

Shea, Thomas M., Bauer, Anne Marries. 1997. Special Education: A Social Systems Perspective. USA: Brown \& Benchmark. A Times Mirror Company.

Deborah Smith Deutsch \& Luckasson Ruth. 1992. Introduction to Special Education. USA: Allyn and Bacon.

Act No. 20 of 2003, On the National Education System. Jakarta. 